\title{
Urate Handling in the Human Body
}

\author{
David Hyndman $^{1} \cdot$ Sha Liu $^{1} \cdot$ Jeffrey N. Miner ${ }^{1}$ \\ Published online: 22 April 2016 \\ (C) The Author(s) 2016. This article is published with open access at Springerlink.com
}

\begin{abstract}
Elevated serum urate concentration is the primary cause of gout. Understanding the processes that affect serum urate concentration is important for understanding the etiology of gout and thereby understanding treatment. Urate handing in the human body is a complex system including three major processes: production, renal elimination, and intestinal elimination. A change in any one of these can affect both the steady-state serum urate concentration as well as other urate processes. The remarkable complexity underlying urate regulation and its maintenance at high levels in humans suggests that this molecule could potentially play an interesting role other than as a mere waste product to be eliminated as rapidly as possible.
\end{abstract}

Keywords Gout $\cdot$ Urate $\cdot$ Uric acid $\cdot$ Excretion $\cdot$ FEUA

\section{Introduction}

Urate is produced during the metabolism of endogenous (typically DNA and RNA) and exogenous (food-derived) purines. Once produced, urate cannot be further metabolized by human cells and so must be eliminated by either renal or extra-renal elimination routes (primarily via the intestine and the intestinal flora). The balance of production and elimination deter-

This article is part of the Topical Collection on Crystal Arthritis

David Hyndman

DHyndman@ardeabio.com

1 Ardea Biosciences, Inc., Biology Department, 9390 Towne Centre Drive, San Diego, CA 92121, USA mines the concentration of urate in the circulation. Urate, with a pKa of 5.3 [1], is also found in its deprotonated form uric acid; however, uric acid represents only $\sim 1 \%$ of the total urate in blood because of the $\mathrm{pH}$. In urine, more of the urate is unprotonated uric acid due to the lower $\mathrm{pH}$ found in urine but at any urine $\mathrm{pH}$ above 5.3, more than half the molecule will be in the form of urate.

Elevated serum urate (sUA) is the primary cause of gout, an inflammatory arthritis induced by monosodium urate crystals. Hyperuricemia is defined as sUA concentrations greater than $6.8 \mathrm{mg} / \mathrm{dl}$, which is the in vitro solubility limit of monosodium urate. Gout occurs in patients with sUA above $6.8 \mathrm{mg} / \mathrm{dl}$ and gout prevalence increases as sUA rises above the $6.8 \mathrm{mg} / \mathrm{dL}$ threshold [2]. International guidelines recommend lowering sUA levels to a target range of $<6 \mathrm{mg} / \mathrm{dL}(<360 \mu \mathrm{mol} / \mathrm{L})$ in all gout case scenarios and below $<5 \mathrm{mg} / \mathrm{dl}(<300 \mu \mathrm{mol} / \mathrm{L})$ in those with greater disease severity and urate burden, such as those with tophi $[3,4]$. Therefore, clarity on the interplay between factors that affect serum urate handling is a key component to understanding and treating gout.

\section{Production}

As noted above, endogenous production of urate derives from the normal cellular metabolism (turnover) of purines such as DNA, RNA, and ATP. The other source of substrates for urate production is dietary purines that are metabolized to urate in the intestine [5-8]. Therefore, the amount of purines in diet can affect urate production, though a significant reduction in dietary purines is required to have clinically relevant decreases in sUA [9-11]. Other factors that appear to impact production are consumption of fructose and beer [12]. As a result of environmental and physiological changes, sUA levels can vary significantly from day to day. 


\section{Elimination}

Elimination of urate occurs via two routes: renal elimination and extra-renal elimination. Urate elimination is a dynamic process mediated by multiple specific import and export transporters in the renal proximal tubule, salivary glands and the intestinal mucosa [13]. The amount of urate excreted via these elimination routes can be quantified as clearance in milliliters per minute of serum (or blood) in the circulation that is cleared. Thus, the total clearance of urate is the sum of the renal clearance and the extra-renal clearance. The total rate of urate removed per minute is the product of the total clearance and the sUA concentration. So, at steady state, for a given rate of production, sUA will settle at a point at which total elimination is equal to production. These relationships form the basis for understanding the dynamics of urate concentration in the serum.

\section{Renal Elimination}

The kidney is typically responsible for approximately 60-65\% of daily urate elimination [14]. Urate in blood is freely filtered in the kidney by the glomerulus. The filtered urate is subjected to significant reabsorption in the proximal tubule. In addition, secretion of urate also occurs. Both these processes are carried out by a series of membrane transporters described later. Of the filtered urate, only $3-10 \%$ is eventually excreted in the urine with the majority reabsorbed in the proximal tubule. Fractional excretion of urate (FEUA) is a description of the net urate reabsorption efficiency of the kidney. FEUA is defined as the percent of filtered urate that is ultimately excreted.

\section{FEUA $=$ excreted urate/filtered urate}

FEUA can be estimated using serum and urine concentrations of urate and creatinine using the following formula which assumes that creatinine clearance is the same as GFR.

$\mathrm{FEUA}=\mathrm{uUA} / \mathrm{uCr} * \mathrm{sCr} / \mathrm{sUA}$

where $u U A$ is the urinary urate concentration, $u C R$ is the urinary creatinine concentration, $s C R$ is the serum creatinine concentration, and $s U A$ is the serum urate concentration.

While hyperuricemia can be caused by overproduction of urate and decreased intestinal excretion of urate, decreased renal excretion or low FEUA represents a major contributor to hyperuricemia. Healthy subjects have an average FEUA in the range of $6-8 \%$, whereas gout patients generally have average FEUA of 3-5\%. As seen in Fig. 1, keeping production, GFR, and extra-renal clearance constant, sUA is a function of FEUA.

After filtration by the glomerulus, the urate passes into the proximal tubule where a large portion of the filtered urate is reabsorbed; a smaller portion of urate is secreted as well.

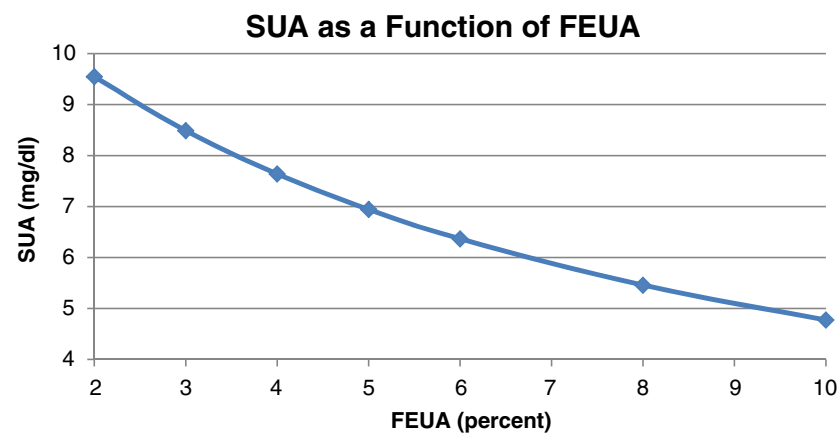

Fig. 1 Holding intestinal clearance constant at $6 \mathrm{ml} / \mathrm{min}$, production constant at $1100 \mathrm{mg} /$ day, and GFR constant at $100 \mathrm{~mL} / \mathrm{min}$, sUA is calculated as production divided by total clearance (extra-renal plus renal clearance)

However, the degree and location of tubular secretion are a subject of controversy. For many years, the accepted model of renal handling of urate, known as the four-component model, was diligently memorized by students in the field. This model was composed of the following four steps: glomerular filtration, almost complete reabsorption, significant secretion, and then subsequent reabsorption of the secreted urate [15]. This model was based on an incorrect assumption regarding the effect of pyrazinamide and lowdose aspirin on urate transporters in the kidney. It was assumed that these drugs caused an inhibition of secretory transporters and much of the research done for many years after that was designed and interpreted based on those assumptions. However, in 1996, using human kidney brush border vesicles, it was observed that pyrazinoic acid (PZA), a metabolite of pyrazinamide, stimulates uptake of urate [16]. Later, after the cloning and expression of the kidney urate transporter, URAT1, it was found that PZA and salicylic acid both trans-stimulate uptake of urate by URAT1, which neatly explains their activity as stimulators of reabsorption rather than inhibitors of secretion [17]. There have been no reports of inhibition of any secretory transporters by these agents. With this knowledge, many publications that were designed to understand the contributions of reabsorption and secretion can be reexamined in light of this new perspective $[15,18]$.

Our current view is that, after glomerular filtration, 90-97\% of urate is reabsorbed in the proximal tubule. Tubular secretion of urate does occur; however, it is not yet clear if the secretion happens concomitantly with reabsorption and/or if there is post-reabsorptive secretion within the tubule.

Given the $\sim 1801$ of water cycled through the kidney each day together with the rapid cycle of urate filtration, reabsorption and secretion, any given molecule of urate may pass through the kidney multiple times a day before being excreted. This is accomplished via an array of renal transporters driving both reabsorption and secretion of urate. 


\section{Reabsorption of Urate in the Kidney}

No method is available to measure renal urate reabsorption directly. However, because urine urate excretion is less than $10 \%$ of the filtered urate load, there is no question that reabsorption represents a significant component of urate handling by the kidney. Various transporters that play a role in reabsorption have been identified and are shown in Fig. 2.

\section{Reabsorption Transporters}

\section{URAT1}

URAT1 ( $S L C 22 A 12)$ has been identified as one of the two most important transporters for urate reabsorption from the apical (luminal) side of the proximal tubule [17]. URAT1 is a typical 12-transmembrane domain protein capable of transporting urate in vitro. Its importance in renal urate reabsorption is confirmed by the observation that individuals who are deficient in functional URAT1 have FEUA of 40-100 \% and extremely low serum urate levels [19]. GWAS studies have demonstrated an important role for URAT1 in both hyperuricemia and gout [20]. Additionally, URAT1 is the target for a number of urate lowering therapies (ULTs) that decrease reabsorption of urate. Indeed, all known drugs capable of increasing FEUA (benzbromarone, probenecid, losartan, and lesinurad) inhibit URAT1. Conversely, there are compounds that raise urate levels by increasing the activity of URAT1 and thereby decreasing FEUA. These include both endogenous compounds (lactate and nicotinate) [17], as well as drugs (pyrazinamide and aspirin) [21-23].

\section{GLUT9}

Glucose transporter 9 (GLUT9, SLC2A9), also referred to as URATv1, is present on the basolateral side of proximal tubule cells of the kidney and is the other transporter fundamental to the reabsorption of urate. GLUT9 is a facilitative transporter of urate shown to be strongly linked to both hyperuricemia and gout in GWAS studies [24-28, 29•]. Several reports of subjects with homozygous inactivating GLUT9 mutations demonstrate that these subjects have no net reabsorption of urate presenting with FEUA's of $100 \%$ or greater. This indicates that it is likely that GLUT9 is the only transporter responsible for the efflux of reabsorbed urate from the interior of the proximal tubule cells back to the blood. GLUT9 actually is present in two different splice variants. The variant SLC2A9$\mathrm{L}$ or long isoform is present on the basolateral side and is responsible for the urate export stage of reabsorption. SLC2A9-S or (short isoform) is expressed in the kidney; however, its function is currently under investigation $[30,31]$.

\section{OAT4}

Organic anion transporter 4 (OAT4; SLC22A11) is capable of transporting organic anions, including hormones and various drugs in vitro and is expressed on the apical membrane of the
Fig. 2 Urate transporters in the kidney - a representative proximal tubule cell is shown with the relevant secretory and resorptive transporters localized to either the basolateral or apical membranes. The arrows denote the direction of transport for substrates. The question marks for urate and selected transporters denote that questions surround the role of these proteins in urate handling in vivo

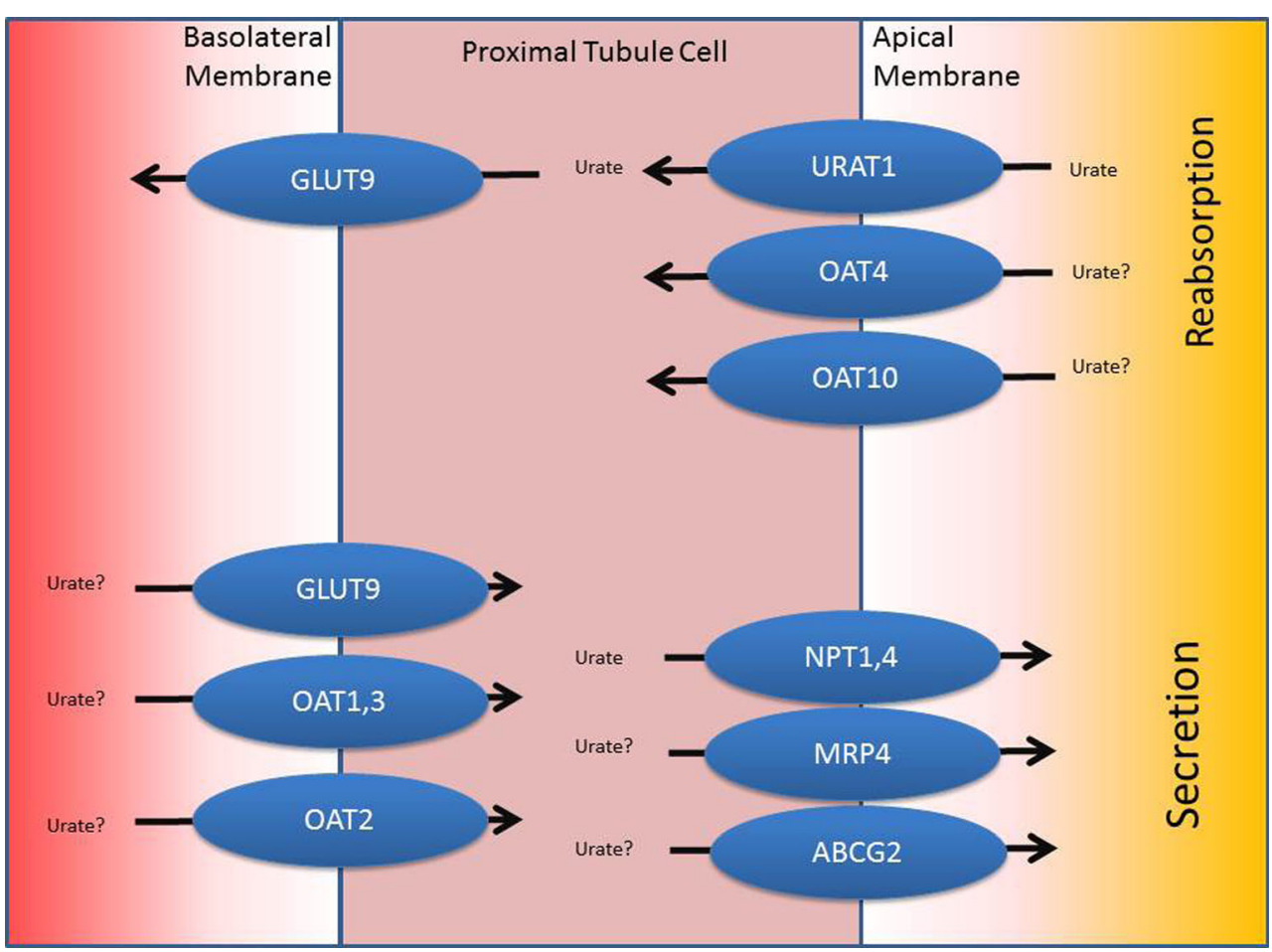


proximal tubule. OAT4 also transports urate and shares sequence similarity to URAT1 [32]. OAT4 is associated with hyperuricemia and gout in many genetic studies [25-28]. Sakiyama et al. reported that patients with the OAT4 variant associated with gout and hyperuricemia exhibited inefficient renal excretion, highlighting the role of OAT4 in renal urate handling [33]. OAT4-mediated urate transport has been reported, although the activity is very low compared to that of URAT1 [34] (unpublished).

\section{OAT10}

OAT10 (SLC22A13) is also present on the apical side of the kidney proximal tubule and has been shown to transport urate with low affinity in vitro. Similar to URAT1, the transport of urate by OAT10 is stimulated by exchange of lactate, pyrazinoate, and nicotinate [35]. However, GWAS studies have not suggested a connection between OAT10 and either gout or hyperuricemia [36•].

\section{Tubular Secretion}

Evidence of tubular secretion of urate was first reported in 1950 in a case study of a subject with hypouricemia that had a defect in reabsorption of urate [37]. Urate clearance was greater than that of inulin, indicating that more urate was being excreted than was being filtered. This can only occur when tubular secretion is present.

Further evidence of tubular secretion of urate was reported by Gutman, Yu, and Berger, who infused patients with intravenous urate to produce very high sUA concentrations [38]. These authors described FEUA values greater than $100 \%$ in these subjects, also consistent with the existence of tubular secretion. More recently, subjects with deactivating mutations of GLUT9 were shown to have, in many cases, FEUA values greater than $100 \%$, once again indicating urate tubular secretion [39]. Finally, the wealth of genetic data (described below) implicating renal secretory transporters in hyperuricemia and the risk of gout cements tubular secretion's role in urate regulation.

The extent to which urate secretion is concomitant with, versus occurs after reabsorption, remains unclear. Publications describing the effect of pyrazinamide on FEUA demonstrated that when subjects are given a high dose of pyrazinamide, the average FEUA is approximately $0.5 \%$. Because the only known effect of pyrazinamide on urate handling is to increase reabsorption by URAT1, this indicates that $0.5 \%$ is the upper limit of post-reabsorptive secretion [15]. However, data from various studies including our own indicate that when sUA is decreased, the FEUA decreases as well but importantly levels off at an FEUA of approximately $2 \%[23,40,41]$ (Liu et al., manuscript in preparation), which indicates that the total contribution of secretion is somewhat higher than the contribution of post-reabsorptive secretion. This leads to the conclusion that a significant component of secretion occurs concomitantly with reabsorption.

\section{Tubular Secretion Transporters}

Several potential renal secretory transporter candidates have been identified. These can be divided into basolateral transporters, which would transport urate from the interstitial fluid into proximal tubule cells, and apical transporters, which would transport urate from proximal tubule cells into the lumen of the proximal tubule.

ABCG2/BCRP (ABCG2), NPT1 (SLC17A1), NPT4 (SLC17A3), and MRP4 (ABCC4) have all been localized on the apical side of the proximal tubule and have all been shown to transport urate in vitro [42-44]. GWAS studies show that ABCG2, NPT1, and NPT4 are associated with hyperuricemia and gout [20, 27, 28, 45]. MRP4 is not associated in these studies, and since no mutations in MRP4 have been found that affect the risk of gout or hyperuricemia, its importance remains unclear. Individual contributions of NPT1 and NPT4 to tubular secretion have been postulated, but their relative roles in the kidney remain incompletely defined. As for ABCG2, the story may be more complicated. ABCG2 was first hypothesized to be functional in renal proximal tubule cells [46]. One study found much higher expression in intestine relative to kidney [47]. Consistent with intestinal expression, the clinical urate excretion phenotype of ABCG2 variants is better explained by an effect on intestinal excretion rather than an effect of urate handling in the kidney, a point discussed more fully later. Since ABCG2's function in the kidney is unclear, NPT4 and NPT1 remain the apical secretory transporters expressed in the renal apical membrane with the most support for a role in the renal secretion of urate.

Which transporters are involved in tubular secretion on the basolateral side of the proximal tubule is a complex question. If, as is believed, much of the secretion occurs in the same cells of the proximal tubule as reabsorption (concomitant secretion), then much of what is secreted could simply be the urate that was previously reabsorbed. But, because GLUT9-deficient subjects have net secretion of urate, this is consistent with import of urate from the interstitium through the basolateral membrane of the tubule. OAT1, OAT2, and OAT3 have been considered the primary candidates for this because they can transport urate in vitro [48], though there is no supporting genetic data for a role for these transporters. Finally, although GLUT9 is clearly a component of the urate reabsorption system functioning as an exporter out of the cell into the interstitium as described earlier, it may also function as an importer with a role in secretion. In vitro, GLUT9 is capable of importing as well as 
exporting urate [49], consistent with its facilitative transport mechanism. It could have a role in the movement of urate from the interstium across the basolateral membrane into the proximal tubule cell as part of the tubular secretion machinery. However, because patients with GLUT9 mutations have evidence for continued secretion, then other transporters are likely involved.

\section{Fractional Excretion of Urate as a Function of sUA}

As mentioned earlier, sUA is determined in part by FEUA. Conversely, FEUA can change as a result of changes in sUA. Several studies have assessed FEUA for the same subjects before and after sUA was modified by means not directly affecting the kidney $[9,18,23,40,50-52]$. These include administration of xanthine oxidase inhibitors, purines, or infusion of urate itself. The results from a wide variety of studies indicate that when sUA is increased in a renal-independent fashion, FEUA increases and similarly when sUA decreases, FEUA decreases, as shown in Fig. 3. This dynamic response to sUA levels is likely an inherent property of the transporters found in the kidney. Interestingly, when FEUA is very low at baseline (as is typically true of gout patients), the FEUA does not decrease as much when sUA decreases and the FEUA does not continue to decrease to zero as sUA drops. Instead, FEUA appears to level off at a specific nonzero point (approximately $2 \%$ FEUA). Our own data has corroborated this understanding (manuscript in preparation). While we have not pushed sUA levels below $2 \mathrm{mg} / \mathrm{dl}$ in our clinical studies, we have detected the point at which FEUA levels off. The fact that FEUA does not go to zero under these conditions is consistent with the presence of tubular secretion of urate. In addition, we have developed a mathematical model of the proximal tubule to calculate FEUA based on principles of transporter kinetics for reabsorption and secretion that fits these observations.

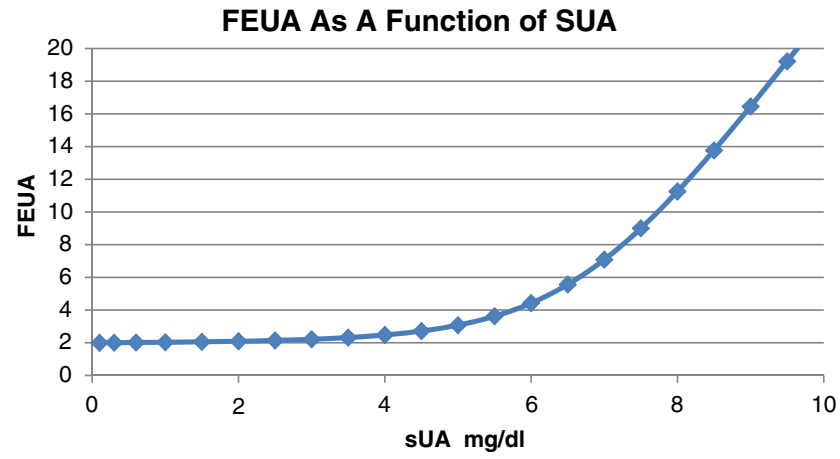

Fig. 3 Representation of our view on the effects of changing sUA on FEUA. This is based on our own clinical analysis as well as data from several publications that have reported that FEUA increases as sUA is increased by purine loading or urate infusion. Also, FEUA has been seen to decrease when sUA is decreased by xanthine oxidase inhibitors or low purine diets but does not go below FEUA of $2 \%$ and apparently levels off as sUA approaches zero $[9,18,23,40,50-52]$

\section{Agents Affecting Renal Handling}

Pyrazinamide, a drug used to treat tuberculosis, significantly increases serum urate levels [22]. Pyrazinoic acid (PZA), a metabolite of pyrazinamide, stimulates URAT1 activity, which decreases renal urate clearance and increases sUA levels $[16,17]$. Low-dose aspirin also causes a decrease in renal clearance of urate. Salicylic acid, the active metabolite of aspirin, stimulates URAT activity [53].

\section{Uricosuric Drugs}

FDA-approved drugs for the treatment of hyperuricemia and gout are known to inhibit URAT1 and include probenecid and lesinurad (Zurampic). Probenecid is an older medication that is uncommonly used in gout due to difficult dosing schedule and prevalent drug-drug interactions. Lesinurad is a recently FDAapproved selective urate resorption inhibitor (SURI) for the treatment of hyperuricemia associated with gout, capable of lowering urate in combination with a xanthine oxidase inhibitor. Lesinurad was also recently approved in Europe for the treatment of gout. Another URAT1 inhibitor, benzbromarone, is approved for use in Japan but is only available on a named patient basis in Europe and is not approved in the USA due to idiosyncratic liver toxicity. Losartan, an antihypertensive agent that has the additional property of lowering urate level, likely has this effect through inhibition of URAT1 [17].

\section{Diuretics}

Long-term treatment with either thiazide or loop diuretics causes a lowering of the renal clearance of urate resulting in an increase in serum urate and the risk of gout [54]. These agents may affect urate levels by multiple mechanisms, and a number of hypotheses have been developed with reasonable supporting data. Hypovolemia resulting from diuretic use may be an important effector of diuretic-induced hyperuricemia. This is demonstrated by the fact that salt restriction, which also causes hypovolemia, produces hyperuricemia that is reversed by salt loading $[55,56]$.

Loop and thiazide diuretics produce an increase in angiotensin II. Angiotensin II increases have been shown to decrease the FEUA resulting in increased sUA [57]. Mechanistically speaking, decreases in FEUA due to angiotensin II may be linked to enhanced URAT1 activity. Increases in angiotensin II cause increased expression of NHE3, a sodium-hydrogen exchanger, among others [58]. NHE3 absorbs sodium and exports hydrogen ions into the lumen of the nephron resulting in a decrease in $\mathrm{pH}$. In vitro URAT1 is more active at lower $\mathrm{pH}$ when expressed in human cells (our unpublished data), so increased activity of NHE3 could result in increased URAT1 activity. Further evidence that increased URAT1 activity is the mechanism of diuretic-induced hyperuricemia is the report that diuretics also 
reduce the clearance of the allopurinol metabolite oxypurinol [59, 60]. Oxypurinol is reabsorbed in the kidney by URAT1 just as urate is [61]. Therefore, it is possible that the decrease in renal clearance of urate due to diuretic use is via an increase in URAT1 activity. However, a genetic association between URAT1 and diuretic induced hyperuricemia has not been found in either published study of this phenomenon.

Other publications suggest the potential involvement of OAT4 in diuretic-induced hyperuricemia. Evidence exists for direct stimulation of OAT4 by hydrochlorothiazide, a thiazide diuretic, and torsemide, a loop diuretic [34, 62], suggesting that this mechanism might be a potential contributor to diuretic-induced hyperuricemia. However, no additional reports of this in vitro phenomenon have surfaced to suggest that all thiazide or loop diuretics would have this same effect. There is conflicting genetic data on OAT4 and diureticinduced hyperuricemia. One study reported an association [63], while another study did not [64]. Testing selective OAT4 inhibitors in clinical trials or detecting nonsynonymous variants in OAT4 with phenotypic effects are two potential approaches to clarify the role of OAT4 in diuretic-induced hyperuricemia.

\section{SGLT2 Inhibitors}

Sodium-dependent glucose transporters are responsible for the active transport of glucose across the proximal tubular membrane. Inhibitors of these transporters prevent renal glucose reabsorption and decrease serum glucose levels significantly. These agents as a class also lower uric acid levels by increasing urinary urate clearance. This effect may be due to the action of glucose on GLUT9mediated urate transport, though the specific mechanism is unclear [30,65].

\section{Intestinal Elimination}

Based on published experiments calculating production [14], the average person excretes approximately $65 \%$ of their daily urate production via the kidney and the remainder via extra-renal elimination. However, some gout patients have been found to excrete only $40 \%$ via the kidney. Therefore, in some subjects, such as those with renal failure, the relative role of extra-renal elimination may be greater.

As in the kidney, urate transporters are likely involved in urate handling in the intestine. Urate enters the intestine either by secretion from the bloodstream, or as a component of bile, saliva, or peptic juices. Once in the intestine, urate can be reabsorbed as evidenced by the fact that Sevelamer, a nonabsorbable, phosphate-binding polymer that also binds urate and can lower serum urate levels. That which is not reabsorbed is degraded by the uricase activity found in the intestinal microbiome resulting in $\mathrm{CO} 2$ or allantoin [66]. Almost no urate is found in feces under normal conditions because of these mechanisms [66].

\section{$A B C G 2$}

ABCG2, also called BCRP, was first identified as a transporter of xenobiotics and was associated with multi-drug resistance to chemotherapeutic drugs. In 2008, ABCG2 was identified in a GWAS study [45] as being associated with serum urate levels, and in 2009, it was found to transport urate in vitro [46]. Genetic validation came when an $\mathrm{ABCG} 2$ variant $(\mathrm{Q} 141 \mathrm{~K})$ associated with elevated serum urate and was found to have less urate transport activity, consistent with a role in excretion of urate [67].

ABCG2 is present in both kidney and intestine, but expression in kidney is weak, whereas expression in the small intestine is very strong [68]. Multiple lines of evidence exist supporting its role in secreting urate into the intestine. Ichida et al. [67] reported that the $\mathrm{ABCG} 2$ risk allele was associated with hyperuricemia in which renal urate excretion is increased. This is consistent with a direct effect on intestinal elimination and an indirect effect on the kidney. Similarly, Dalbeth et al. reported that subjects with the Q141K risk variant have not only higher SUA but also slightly higher FEUA [69•]. More recently, Matsuo et.al [70] also reported that the ABCG2 variant responsible for hyperuricemia increased FEUA. In contrast, Kottgen et.al. [36•] reported that FEUA is lower in those with the ABCG2 variants associated with hyperuricemia. The Kottgen report is the outlier in this case, and it is difficult to reconcile this result with the others. One explanation for why an increase in FEUA might be observed in patients with $\mathrm{ABCG} 2$ dysfunction is that lack of intestinal secretion raises sUA which in turn can indirectly increase FEUA, as mentioned earlier.

One other intestinal transporter that may play a role is NPT5 (SLC17A4). This transporter is an anion exporter with homology to sodium-phosphate cotransporters and is specifically expressed on the intestinal brush border membrane. It can transport urate in vitro [71]. Furthermore, genome-wide association studies have identified the cluster that includes NPT5 as being associated with circulating urate concentration [72], an important potential hint as to its role in gout.

\section{Conclusions}

Urate handling is a complex, dynamic balance between three major processes: production, renal elimination, and intestinal elimination. A change in any one of these can affect both the steady-state serum urate concentration as well as other urate processes. The remarkable complexity underlying urate regulation and its maintenance at high levels in humans suggests that this molecule could potentially play an interesting role other than as a mere waste product to be eliminated as rapidly as possible. 
Acknowledgments We thank David Mount for providing clarity on the mechanisms of diuretic-induced hyperuricemia and Phil Tan and Scott Adler for providing helpful comments on the manuscript.

\section{Compliance with Ethical Standards}

Conflict of Interest DH reports stock in AstraZeneca and employment by Ardea Biosciences, Inc., outside the submitted work. SL reports stock in AstraZeneca and employment by Ardea Biosciences, Inc., outside the submitted work. JNM reports stock in AstraZeneca and employment by Ardea Biosciences, Inc., outside the submitted work.

Human and Animal Rights and Informed Consent All reported studies/experiments with human or animal subjects performed by the authors have been previously published and were in compliance with all applicable ethical standards (including the Helsinki declaration and its amendments, institutional/national research committee standards, and international/national/institutional guidelines).

Open Access This article is distributed under the terms of the Creative Commons Attribution 4.0 International License (http:// creativecommons.org/licenses/by/4.0/), which permits unrestricted use, distribution, and reproduction in any medium, provided you give appropriate credit to the original author(s) and the source, provide a link to the Creative Commons license, and indicate if changes were made.

\section{References}

Papers of particular interest, published recently, have been highlighted as:

- Of importance

1. Wang Z, Königsberger E. Solubility equilibria in the uric acidsodium urate-water system. Thermochim Acta. 1998;310:237-42.

2. Choi HK, Mount DB, Reginato AM. Pathogenesis of gout. Ann Intern Med. 2005;143(7):499-516.

3. Zhang W, Doherty M, Bardin T, Pascual E, Barskova V, Conaghan $\mathrm{P}$, et al. EULAR evidence based recommendations for gout, part II: management: report of a task force of the EULAR Standing Committee for International Clinical Studies Including Therapeutics (ESCISIT). Ann Rheum Dis. 2006;65(10):1312-24. doi:10.1136/ard.2006.055269.

4. Khanna D, Fitzgerald JD, Khanna PP, Bae S, Singh MK, Neogi T, et al. 2012 American College of Rheumatology guidelines for management of gout, part 1: systematic nonpharmacologic and pharmacologic therapeutic approaches to hyperuricemia. Arthritis Care Res. 2012;64(10):1431-46. doi:10.1002/acr.21772.

5. Oh JH, Dossetor JB, Beck IT. Kinetics of uric acid transport and its production in rat small intestine. Can J Physiol Pharmacol. 1967;45(1):121-7.

6. Bronk JR, Shaw MI. The transport of uric acid across mouse small intestine in vitro. J Physiol. 1986;378:229-39.

7. Dukes CE, Steplock DA, Kahn AM, Weinman EJ. The transport of urate in the small intestine of the rat. Proc Soc Exp Biol Med. 1982;171(1):19-23.

8. Wilson DW, Wilson HC. Studies in vitro of the digestion and absorption of purine ribonucleotides by the intestine. J Biol Chem. 1962;237:1643-7.
9. Löffler W, Gröbner W, Medina R, Zöllner N. Influence of dietary purines on pool size, turnover, and excretion of uric acid during balance conditions: isotope studies using ${ }^{15} \mathrm{~N}$-uric acid. Res Exp Med (Berl). 1982;181(2):113-23.

10. Yamamoto T, Yokoyama H, Moriwaki Y, Takahashi S, Suda M, Hada T, et al. The effect of completely purine-free diet of low sodium content on purine intermediates and end-product. Eur J Clin Nutr. 1990;44(9):659-64.

11. Porcelli B, Vannoni D, Leoncini R, Pizzichini M, Pagani R, Marinello E. Free oxypurines in plasma and urine of gout patients before and after a purine-free diet. Adv Exp Med Biol. 1994;370: $47-52$.

12. Choi HK, Atkinson K, Karlson EW, Willett W, Curhan G. Purinerich foods, dairy and protein intake, and the risk of gout in men. $\mathrm{N}$ Engl J Med. 2004;350(11):1093-103. doi:10.1056/ NEJMoa035700.

13. Ikarashi R, Shibasaki K, Yamaguchi A. Immunohistochemical studies of organic anion transporters and urate transporter 1 expression in human salivary gland. Acta Odontol Scand. 2012. doi:10. 3109/00016357.2012.680904.

14. Sorensen LB. Role of the intestinal tract in the elimination of uric acid. Arthritis Rheum. 1965;8(5):694-706.

15. Levinson DJ, Sorensen LB. Renal handling of uric acid in normal and gouty subjects: evidence for a 4-component system. Ann Rheum Dis. 1980;39(2):173-9.

16. Roch-Ramel F, Guisan B, Schild L. Indirect coupling of urate and p-aminohippurate transport to sodium in human brush-border membrane vesicles. Am J Physiol. 1996;270(1):F61-F8.

17. Enomoto A, Kimura H, Chairoungdua A, Shigeta Y, Jutabha P, Cha $\mathrm{SH}$, et al. Molecular identification of a renal urate anion exchanger that regulates blood urate levels. Nature. 2002;417(6887):447-52. doi:10.1038/nature742.

18. Rieselbach RE, Sorensen LB, Shelp WD, Steele TH. Diminished renal urate secretion per nephron as a basis for primary gout. Ann Intern Med. 1970;73(3):359-66.

19. Ichida K, Hosoyamada M, Hisatome I, Enomoto A, Hikita M, Endou $\mathrm{H}$, et al. Clinical and molecular analysis of patients with renal hypouricemia in Japan-influence of URAT1 gene on urinary urate excretion. J Am Soc Nephrol. 2004;15(1):164-73. doi:10. 1097/01.asn.0000105320.04395.d0.

20. Kottgen A, Albrecht E, Teumer A, Vitart V, Krumsiek J, Hundertmark C, et al. Genome-wide association analyses identify 18 new loci associated with serum urate concentrations. Nat Genet. 2013;45(2):145-54. doi:10.1038/ng.2500.

21. Diamond HS, Paolino JS. Evidence for a postsecretory reabsorptive site for uric acid in man. J Clin Invest. 1973;52(6):1491-9. doi:10. 1172/JCI107323.

22. Solangi GA, Zuberi BF, Shaikh S, Shaikh WM. Pyrazinamide induced hyperuricemia in patients taking anti-tuberculous therapy. J Coll Physicians Surg Pak. 2004;14(3):136-8.

23. Berliner RW, Hilton JG, Yu TF, Kennedy TJ. The renal mechanism for urate excretion in man. J Clin Invest. 1950;29(4):396-401. doi: 10.1172/JCI102271.

24. Gunjaca G, Boban M, Pehlic M, Zemunik T, Budimir D, Kolcic I, et al. Predictive value of 8 genetic loci for serum uric acid concentration. Croat Med J. 2010;51(1):23-31.

25. van der Harst P, Bakker SJ, de Boer RA, Wolffenbuttel BH, Johnson T, Caulfield MJ, et al. Replication of the five novel loci for uric acid concentrations and potential mediating mechanisms. Hum Mol Genet. 2010;19(2):387-95. doi:10.1093/hmg/ddp489.

26. Yang Q, Kottgen A, Dehghan A, Smith AV, Glazer NL, Chen MH, et al. Multiple genetic loci influence serum urate levels and their relationship with gout and cardiovascular disease risk factors. Circ Cardiovasc Genet. 2010. doi:10.1161/CIRCGENETICS.109. 934455. 
27. Kolz M, Johnson T, Sanna S, Teumer A, Vitart V, Perola M, et al. Meta-analysis of 28,141 individuals identifies common variants within five new loci that influence uric acid concentrations. PLoS Genet. 2009;5(6):e1000504. doi:10.1371/journal.pgen.1000504.

28. Phipps-Green AJ, Merriman ME, Topless R, Altaf S, Montgomery GW, Franklin C, et al. Twenty-eight loci that influence serum urate levels: analysis of association with gout. Ann Rheum Dis. 2014. doi:10.1136/annrheumdis-2014-205877.

29. Matsuo H, Yamamoto K, Nakaoka H, Nakayama A, Sakiyama M, Chiba T et al. Genome-wide association study of clinically defined gout identifies multiple risk loci and its association with clinical subtypes. Ann Rheum Dis. 2015. doi:10.1136/annrheumdis-2014206191. This paper confirms the association of ABCG2 with hyperuricemia and gout and also finds that FEUA is unexpectedly increased with the allele which also increases SUA

30. Witkowska K, Smith KM, Yao SY, Ng AM, O'Neill D, Karpinski E, et al. Human SLC2A9a and SLC2A9b isoforms mediate electrogenic transport of urate with different characteristics in the presence of hexoses. Am J Physiol Renal Physiol. 2012;303(4):F527-39. doi:10.1152/ajprenal.00134.2012.

31. Kimura T, Takahashi M, Yan K, Sakurai H. Expression of SLC2A9 isoforms in the kidney and their localization in polarized epithelial cells. PLoS One. 2014;9(1):e84996. doi:10.1371/journal.pone. 0084996.

32. Zhou F, Zhu L, Cui PH, Church WB, Murray M. Functional characterization of nonsynonymous single nucleotide polymorphisms in the human organic anion transporter 4 (hOAT4). Br J Pharmacol. 2010;159(2):419-27. doi:10.1111/j.1476-5381.2009. 00545.x.

33. Sakiyama M, Matsuo H, Shimizu S, Nakashima H, Nakayama A, Chiba $\mathrm{T}$, et al. A common variant of organic anion transporter 4 (OAT4/SLC22A11) gene is associated with renal underexcretion type gout. Drug Metab Pharmacokinet. 2014;29(2):208-10.

34. Hagos Y, Stein D, Ugele B, Burckhardt G, Bahn A. Human renal organic anion transporter 4 operates as an asymmetric urate transporter. J Am Soc Nephrol. 2007;18(2):430-9. doi:10.1681/ASN. 2006040415

35. Bahn A, Hagos Y, Reuter S, Balen D, Brzica H, Krick W, et al. Identification of a new urate and high affinity nicotinate transporter, hOAT10 (SLC22A13). J Biol Chem. 2008;283(24):16332-41. doi: 10.1074/jbc.M800737200.

36. Köttgen A, Albrecht E, Teumer A, Vitart V, Krumsiek J, Hundertmark $\mathrm{C}$ et al. Genome-wide association analyses identify 18 new loci associated with serum urate concentrations [published online ahead of print December 23, 2012]. Nat Genet 2012 doi:10. 1038/ng.2500. This paper found that the ABCG2 variant that is associated with increased SUA is also associated with decreased FEUA.

37. Praetorius E, Kirk JE. Hypouricemia: with evidence for tubular elimination of uric acid. J Lab Clin Med. 1950;35(6):865-8.

38. Gutman AB, Yu TF, Berger L. Tubular secretion of urate in man. $\mathrm{J}$ Clin Invest. 1959;38:1778-81. doi:10.1172/JCI103956.

39. Dinour D, Gray NK, Campbell S, Shu X, Sawyer L, Richardson W, et al. Homozygous SLC2A9 mutations cause severe renal hypouricemia. J Am Soc Nephrol. 2010;21(1):64-72. doi:10. 1681/ASN.2009040406.

40. Puig JG, Torres RJ, de Miguel E, Sanchez A, Bailen R, Banegas JR. Uric acid excretion in healthy subjects: a nomogram to assess the mechanisms underlying purine metabolic disorders. Metabolism. 2012;61(4):512-8. doi:10.1016/j.metabol.2011.08.005.

41. Perez-Ruiz F, Calabozo M, Erauskin GG, Ruibal A, Herrero-Beites AM. Renal underexcretion of uric acid is present in patients with apparent high urinary uric acid output. Arthritis Rheum. 2002;47(6):610-3. doi:10.1002/art.10792.

42. El-Sheikh AA, van den Heuvel JJ, Koenderink JB, Russel FG. Effect of hypouricaemic and hyperuricaemic drugs on the renal urate efflux transporter, multidrug resistance protein 4 . Br J Pharmacol. 2008;155(7):1066-75. doi:10.1038/bjp.2008.343.

43. Jutabha P, Anzai N, Kitamura K, Taniguchi A, Kaneko S, Yan K, et al. Human sodium phosphate transporter 4 (hNPT4/SLC17A3) as a common renal secretory pathway for drugs and urate. J Biol Chem. 2010;285(45):35123-32. doi:10.1074/jbc.M110.121301.

44. Iharada M, Miyaji T, Fujimoto T, Hiasa M, Anzai N, Omote H, et al. Type 1 sodium-dependent phosphate transporter (SLC17A1 Protein) is a $\mathrm{Cl}^{-}$-dependent urate exporter. J Biol Chem. 2010;285(34):26107-13. doi:10.1074/jbc.M110.122721.

45. Dehghan A, Köttgen A, Yang Q, Hwang SJ, Kao WL, Rivadeneira $\mathrm{F}$, et al. Association of three genetic loci with uric acid concentration and risk of gout: a genome-wide association study. Lancet. 2008;372(9654):1953-61. doi:10.1016/S0140-6736(08)61343-4.

46. Woodward OM, Kottgen A, Coresh J, Boerwinkle E, Guggino WB, Kottgen M. Identification of a urate transporter, ABCG2, with a common functional polymorphism causing gout. Proc Natl Acad Sci U S A. 2009;106(25):10338-42. doi:10.1073/pnas. 0901249106.

47. Maliepaard M, Scheffer GL, Faneyte IF, van Gastelen MA, Pijnenborg AC, Schinkel AH, et al. Subcellular localization and distribution of the breast cancer resistance protein transporter in normal human tissues. Cancer Res. 2001;61(8):3458-64.

48. Enomoto A, Endou H. Roles of organic anion transporters (OATs) and a urate transporter (URAT1) in the pathophysiology of human disease. Clin Exp Nephrol. 2005;9(3):195-205. doi:10.1007/ s10157-005-0368-5.

49. Caulfield MJ, Munroe PB, O'Neill D, Witkowska K, Charchar FJ, Doblado M, et al. SLC2A9 is a high-capacity urate transporter in humans. PLoS Med. 2008;5(10), e197. doi:10.1371/journal.pmed. 0050197.

50. Steele TH, Rieselbach RE. The renal mechanism for urate homeostasis in normal man. Am J Med. 1967;43(6):868-75.

51. Gutman AB, Yu TF, Berger L. Renal function in gout. 3. Estimation of tubular secretion and reabsorption of uric acid by use of pyrazinamide (pyrazinoic acid). Am J Med. 1969;47(4):575-92.

52. Yu TS, Berger L, Gutman AB. Renal function in gout. II. Effect of uric acid loading on renal excretion of uric acid. Am J Med. 1962;33:829-44.

53. Ohtsu N, Anzai N, Fukutomi T, Kimura T, Sakurai H, Endou H. Human renal urate transporter URAT1 mediates the transport of salicylate [in Japanese]. Nihon Jinzo Gakkai shi. 2010;52(4):499504.

54. Reese Jr OG, Steele TH. Renal transport of urate during diureticinduced hypouricemia. Am J Med. 1976;60(7):973-9.

55. Masugi F, Ogihara T, Hashizume K, Hasegawa T, Sakaguchi K, Kumahara Y. Changes in plasma lipids and uric acid with sodium loading and sodium depletion in patients with essential hypertension. J Hum Hypertens. 1988;1(4):293-8.

56. Del Rio A, Rodriguez-Villamil JL. Metabolic effects of strict salt restriction in essential hypertensive patients. J Intern Med. 1993;233(5):409-14.

57. Moriwaki Y, Yamamoto T, Tsutsumi Z, Takahashi S, Hada T. Effects of angiotensin II infusion on renal excretion of purine bases and oxypurinol. Metabolism. 2002;51(7):893-5.

58. Riquier-Brison AD, Leong PK, Pihakaski-Maunsbach K, McDonough AA. Angiotensin II stimulates trafficking of NHE3, $\mathrm{NaPi}$, and associated proteins into the proximal tubule microvilli. Am J Physiol Renal Physiol. 2010;298(1):F177-86. doi:10.1152/ ajprenal.00464.2009.

59. Löffler W, Landthaler R, de Vries JX, Walter-Sack I, Ittensohn A, Voss A, et al. Interaction of allopurinol and hydrochlorothiazide during prolonged oral administration of both drugs in normal subjects, I: uric acid kinetics. Clin Investig. 1994;72(12):1071-5.

60. Wright DF, Stamp LK, Merriman TR, Barclay ML, Duffull SB, Holford NH. The population pharmacokinetics of allopurinol and 
oxypurinol in patients with gout. Eur J Clin Pharmacol. 2013;69(7): 1411-21. doi:10.1007/s00228-013-1478-8.

61. Iwanaga T, Kobayashi D, Hirayama M, Maeda T, Tamai I. Involvement of uric acid transporter in increased renal clearance of the xanthine oxidase inhibitor oxypurinol induced by a uricosuric agent, benzbromarone. Drug Metab Dispos. 2005;33(12):17915. doi:10.1124/dmd.105.006056.

62. Hagos Y, Bahn A, Vormfelde SV, Brockmoller J, Burckhardt G. Torasemide transport by organic anion transporters contributes to hyperuricemia. J Am Soc Nephrol. 2007;18(12):3101-9. doi:10. 1681/ASN.2007010106.

63. McAdams-DeMarco MA, Maynard JW, Baer AN, Kao LW, Kottgen A, Coresh J. A urate gene-by-diuretic interaction and gout risk in participants with hypertension: results from the ARIC study. Ann Rheum Dis. 2013;72(5):701-6. doi:10.1136/annrheumdis2011-201186.

64. Bao Y, Curhan G, Merriman T, Plenge R, Kraft P, Choi HK. Lack of gene-diuretic interactions on the risk of incident gout: the Nurses' Health Study and Health Professionals Follow-up Study. Ann Rheum Dis. 2015;74(7):1394-8. doi:10.1136/annrheumdis-2014206534.

65. Chino Y, Samukawa Y, Sakai S, Nakai Y, Yamaguchi J, Nakanishi $\mathrm{T}$, et al. SGLT2 inhibitor lowers serum uric acid through alteration of uric acid transport activity in renal tubule by increased glycosuria. Biopharm Drug Dispos. 2014;35(7):391-404. doi:10.1002/ bdd.1909.
66. Sorensen LB. Degradation of uric acid in man. Metabolism. 1959;8(5):687-703.

67. Ichida K, Matsuo H, Takada T, Nakayama A, Murakami K, Shimizu T, et al. Decreased extra-renal urate excretion is a common cause of hyperuricemia. Nat Commun. 2012;3:764. doi:10.1038/ ncomms 1756 .

68. Uhlen M, Fagerberg L, Hallstrom BM, Lindskog C, Oksvold P, Mardinoglu A, et al. Proteomics. Tissue-based map of the human proteome. Science. 2015;347(6220):1260419. doi:10.1126/science. 1260419.

69. Dalbeth N, House ME, Gamble GD, Pool B, Horne A, Purvis L, et al. Influence of the ABCG2 gout risk $141 \mathrm{~K}$ allele on urate metabolism during a fructose challenge. Arthritis Res Ther. 2014;16(1):R34. doi:10.1186/ar4463. This paper demonstrates both the increased SUA and the increased FEUA of subjects with the ABCG2 risk allele.

70. Matsuo H, Nakayama A, Sakiyama M, Chiba T, Shimizu S, Kawamura Y, et al. ABCG2 dysfunction causes hyperuricemia due to both renal urate underexcretion and renal urate overload. Sci Rep. 2014;4:3755. doi:10.1038/srep03755.

71. Togawa N, Miyaji T, Izawa S, Omote H, Moriyama Y. $\mathrm{A} \mathrm{Na}^{+}$phosphate cotransporter homologue (SLC17A4 protein) is an intestinal organic anion exporter. Am J Physiol Cell Physiol. 2012;302(11):C1652-C60. doi:10.1152/ajpcell.00015.2012.

72. Lee YH, Song GG. Pathway analysis of genome-wide association studies on uric acid concentrations. Hum Immunol. 2012;73(8): 805-10. doi:10.1016/j.humimm.2012.05.004. 